\title{
ALÉM DOS SENTIDOS: CULTURA E IDENTIDADE SURDAS COMO DISCURSO CAPITALÍSTICO DE PRODUÇÃO DE SUBJETIVIDADES E SERIALIZAÇÃO DO SER VISOSSINALIZANTE ***
}

\author{
BEYOND THE SENSES: DEAF CULTURE AND IDENTITY AS A CAPITALISTIC \\ DISCOURSE OF SUBJECTIVITIES PRODUCTION AND SERIALIZATION OF DEAF \\ SIGN LANGUAGE USERS
}

Claudio Alves Benassi 1

Recebido: 12 mar. 2019

Aceite: 17 mai. 2019

DOI https://doi.org/10.29327/2.1373.1-6

RESUMO Neste artigo, apresento um esboço de minha pesquisa ainda em desenvolvimento a respeito das identidades e cultura surdas, que as analisará como um discurso capitalístico de produção de subjetividade e serialização (padronização) do ser visossinalizante. A situação da língua de sinais é brevemente contextualizada, são expostos os conceitos de cultura surda e as identidades surdas e suas características são apresentadas em série decrescente. Na sequência, baseado na concepção de micropolítica de Guattari e Rolnik (1996), busco entender a produção de subjetividade e serialização do ser visossinalizante por meio do discurso em torno da cultura e da identidade, que visa tornar estes sujeitos padronizados. A hipótese de ruptura com o discurso capitalístico serializador se daria por meio da singularização do ser visossinalizante em duas esferas: a cotidiana e acadêmica e a cultural e artística.

PALAVRAS-CHAVE: Micropolítica. Singularização. Cultura e identidades surdas.

ABSTRACT: in this article I present an outline of my research still in project about deaf identities and cultures, which will analyze them as a capitalistic discourse of subjectivity production and serialization - standardization - of deaf sign language users. The situation of sign language is briefly contextualized, the concepts of deaf culture and deaf identities are exposed, and their characteristics are presented in descending series. After, I seek to understand, based on Guattari and

\footnotetext{
* Artigo desenvolvido na Disciplina Subjetividade e arte contemporânea, do Programa de pós-graduação em estudos de cultura contemporânea - ECCO. Doutorado, da Universidade Federal de Mato Grosso - UFMT.

** Visossinalizante é um desdobramento do termo "visual" desenvolvido por Duarte (2016), baseado nas características do sujeito quanto à produção, à emissão e à recepção linguística. Neste sentido, o sujeito que se comunica pelo campo viso-espacial é também por ele caracterizado e nomeado.

1 Doutorado em Estudos de Linguagens pela Universidade Federal Mato Grosso (UFMT). Docente na Universidade Federal Mato Grosso (UFMT). E-mail. claudiobenassi@cdp.ufmt.br ORCID iD https://orcid.org/0000-0002-7698-1998
} 
Rolnik's micropolitics conception (1996) the production of subjectivity and serialization of deaf sign language users, through the discourse around this subject's culture and identity, which aims to make them standardized. The hypothesis of rupture with the serialized capitalistic discourse, would occur through the singularization of deaf sign language users into two spheres: daily and academic and cultural and artistic.

KEYWORDS: Micropolitics. Singularization. Deaf culture and identities.

\section{PRIMEIRAS PALAVRAS: CONTEXTUALIZAÇÃO}

Este artigo é um esboço do objeto de pesquisa a respeito da cultura e das identidades surdas como um discurso capitalístico de produção e serialização do ser visossinalizante (surdo). O interesse por este tema surge da vivência com sujeitos visossinalizantes e dos aspectos físicos da surdez que os constituem, além do meu próprio processo de perda auditiva, decorrente de doença hereditária.

A Língua de Sinais - doravante LS - é considerada uma língua jovem (DUARTE, 2013) e ao contrário do que muitos pensam, não é universal. Cada país tem sua LS, que incorpora a cultura e a ideologia do falante. No Brasil, a Linguagem de Sinais surge com o professor francês Eduart Huet (1822-1882), grande responsável pelo estruturação da LS nas terras tupiniquins.

Por meio de movimentos da comunidade organizada - visossinalizantes, familiares, profissionais do ensino e da interpretação de LS, políticos e artistas, a então Linguagem de Sinais Brasileiras é reconhecida como a Língua Brasileira de Sinais - LIBRAS, pela Lei n.10.436, de 22 de abril de 2002, como sendo um sistema linguístico, com gramática própria oriunda das comunidades de visossinalizantes do Brasil (BRASIL, 2002).

A partir deste evento, houve um aumento significativo do interesse pela LS. No entanto, o número de pesquisas não cresceu na mesma proporção, o que fez proliferar ideais equivocadas e senso comum a respeito da língua, inclusive no meio acadêmico. Poucas são as pesquisas que investigam a linguísticas e temas relacionados a ela, sendo que as existentes tem como foco o seu aspecto pedagógico, quase sempre realizadas por pesquisadores ouvintes.

O objetivo deste recorte da minha pesquisa é discorrer a respeito do conceito de cultura surda e seus artefatos culturais engendrados no meio e buscar as definições das identidades surdas, 
analisando-as como um discurso capitalístico que produz a subjetividade e serializa o ser visossinalizante.

\section{INTRODUÇÃO À SUBJETIVIDADE CAPITALÍSTICA E A SERIALIZACÃO DO VISOSSINALIZANTE}

Para Félix Guattari e Suely Rolnik (1996), assim como nas linhas de produção se acrescenta moléculas ao leite até que se obtenha como produto final o leite condensado, nos sujeitos são injetadas representações "como parte de um processo de produção subjetiva". Por meio da imersão do indivíduo nessas representações, o desejo do ter/ser e do querer possuir são produzidos. Para os autores não se produz somente uma subjetividade individual, produz-se também a subjetividade social, que se pode encontrar em todos os níveis da produção e do consumo e, ainda mais, produz-se uma subjetividade inconsciente.

Falando do ser visossinalizante, por meio do discurso de identidades surdas - que o levariam a adquirir uma determinada cultura, a dita "cultura surda" - o capital injeta no sujeito o desejo de fazer parte desse universo, fazendo com que o visossinalizante passe a reproduzir os modos de existência criados nas linhas de produção de subjetividade. A pretexto de uma suposta valorização, o visossinalizante é imerso no que Guattari e Rolnik (1996) chamam de “agenciamentos de enunciação".

A princípio, o visossinalizante é exposto a um conceito de cultura duplamente empobrecido (SAHLINS, 1997, p. 43), pelo qual se faz a marcação da diferença e se constrói uma história impura construída nas entranhas do capitalismo. Esse agenciamento produz no visossinalizante um sentimento de inferioridade e o leva a se revoltar com os ouvintes, os quais denominam ouvintistas. Neste aspecto, o visossinalizante é levado a acreditar que deve se agrupar com pares mais avançados, se aproximar das associações e federações de visossinalizantes, onde adquirirá uma identidade surda e, consequentemente, a cultura surda.

O visossinalizante então passa a reproduzir os mesmos agenciamentos, pois "tudo leva a esse tipo de economia" (GUATTARI; RONILCK, 1996, p. 12). Na "linha de montagem" o 
visossinalizante é inferiorizado, fragilizado e levado a se alienar, mediante uma falsa ideia de proteção. Para os autores, “muitas vezes não há outra saída. É que quando na desmontagem, perplexos e desparametrados, nos fragilizamos, a tendência é adotar posições meramente defensivas" (op. cit.).

A surdez é usada como um agenciamento para alienar o visossinalizante quanto a desobrigação da aprendizagem da língua oral escrita. E, em função da modalidade visual da língua que ele utiliza, são reivindicadas desde provas das disciplinas cursadas no ensino básico até provas em concursos públicos em sinalização em vídeo. Outras ocorrências da influência desses agenciamentos podem ser citados como, por exemplo, um de nossos alunos, que se recusou a pagar a taxa de inscrição em um evento alegando que não faz parte da cultura surda.

Uma de nossas colegas de trabalho - professora visossinalizante - foi segregada pela comunidade surda, pois consideraram que ela perdeu a cultura e a identidade surda ao ser aprovada em concurso público em instituição que é reduto de estudo e pesquisa da LIBRAS, principalmente no que tange à linguística e à gramática - em sua maioria realizadas por ouvintes.

Outras duas alunas visossinalizantes do curso de Letras-Libras - Licenciatura, da mesma instituição, são excluídas do grupo de alunos visossinalizantes por oralizarem, utilizarem a escrita e não utilizarem a LS exclusivamente. Se aceitar tais aspectos, o visossinalizante acredita que perderá sua identidade e, consequentemente, a sua cultura, a qual, para o visossinalizante, funciona como uma "carapaça" que o protege contra os malefícios provocados pelos ouvintes.

Por medo da marginalização na qual corremos o risco de ser confinados quando ousamos criar qualquer território singular, isto é, independente de serializações subjetivas; por medo de essa marginalização chegar a comprometer até a própria possibilidade de sobrevivência (o que é plenamente possível), acabamos reivindicando um território no edifício das identidades reconhecidas. (GUATTARI; ROLNIK, 1996, p. 12).

Para obter certos benefícios e/ou regalias, o visossinalizante - ou até mesmo profissionais mal-intencionados - usam a surdez para justificar dificuldades de aprendizagem, diferenças comportamentais, cognitivas e culturais, e, ainda, para reivindicar direitos, muitos dos quais existentes apenas na concepção desses sujeitos. Para os autores, “tornamo-nos assim - muitas vezes 
em dissonância com nossa consciência - produtores de algumas sequências da linha de montagem do desejo" (op. cit.).

O visossinalizante exposto a tal agenciamento passa a reproduzir o discurso da importância de pertencimento à comunidade, da adequação a uma identidade surda e da aquisição da cultura surda. Percebe-se então que o mesmo foi "normalizado" por meio da cultura que para Guattari e Rolnik (1996) produz indivíduos "articulados uns aos outros, segundo sistemas hierárquicos, sistemas de valores, sistemas de submissão", não visíveis e explícitos, outrossim, dissimulados.

Para os autores,

[...] o capital funciona de modo complementar à cultura enquanto conceito de equivalência: o capital ocupa-se da sujeição econômica, e a cultura, da sujeição subjetiva. E quando falo em sujeição subjetiva não me refiro apenas à publicidade para a produção e o consumo de bens. É a própria essência do lucro capitalista que não se reduz ao campo da mais-valia econômica: ela está também na tomada de poder da subjetividade (GUATTARI; ROLNIK, 1996, p. 16. Grifo dos autores).

O visossinalizante é "ensinado" a recusar aspectos e características do mundo ouvinte, como, por exemplo, a escrita da língua oral, a oralidade, a leitura labial - elementos que, como fazem parte de sua Segunda Língua (L2) constituem o bilinguismo juntamente com a LIBRAS como Primeira Língua (L1) e são essenciais para que possa transitar satisfatoriamente na comunidade linguística majoritária. Sob alegação da cultura linguística diferente (sinalizada), o visossinalizante se recusa veementemente à língua oral por acreditar que tem sua língua própria e que deve se comunicar nela.

Essa repulsa é produzida pela subjetividade capitalística que o faz serializado. As consequências são a redução do universo linguístico do visossinalizante, uma vez que a língua de sinais está restrita à educação, à igreja e à família. Outra grave consequência na recusa da aprendizagem da escrita é a precariedade na fixação do conhecimento pelo sujeito com surdez e o afastamento dos centros produtores de conhecimento, como a academia.

Para o capital, usar as identidades e a cultura surdas para serializar o ser visossinalizante fazendo-o recusar a escrita ou a oralização é extremamente benéfico. "Produzir" um visossinalizante que se negue à escrita é mais barato que formar professores de Língua Portuguesa como L2. "Fabricar" um visossinalizante que se recuse à oralidade é muito mais vantajoso que 
pagar implante coclear de qualidade e profissionais das áreas de psicologia e fonoaudiologia para que se restitua esse sujeito à sociedade.

\section{CULTURA E IDENTIDADES SURDAS}

\subsection{Cultura surda: conceito e artefatos culturais}

Após ser o reconhecimento, a Libras tornou-se modismo na comunidade acadêmica. $\mathrm{O}$ número que intérpretes - que antes estavam circunscritos às igrejas - cresceu, como também cresceu o interesse de professores a respeito do tema. Apesar da temática despertar o interesse de muitos pesquisadores, ainda podemos considerar que o número de pesquisas na área é incipiente. As pesquisas giram em torno da linguística, da gramática, da formação de profissionais, e quase sempre desenvolvidas por ouvintes. Dentre outros assuntos, cultura e identidade surdas são os temas preferidos pelos pesquisadores.

No senso comum, o entendimento do sujeito com surdez a respeito da chamada "cultura surda" é baseado no diferentismo. Isto é, está pautado por uma diferença biológica que o condiciona à língua de sinais. Ao ser questionado, o visossinalizante justifica sua cultura por perceber o mundo e nele se expressar por meio de uma língua de natureza visual-motora. Tal proposição, justifica para o sujeito a existência de uma cultura mediante o uso de uma língua de sinais que se diferencia da língua da maioria linguística oral-auditiva.

Para a pesquisadora Ana Paula Santana,

$\mathrm{Na}$ área da surdez, geralmente se encontra o termo "cultura" como referência à língua (de sinais) às estratégias sociais e aos mecanismos compensatórios de que os surdos usufruem para agir no/sobre o mundo, como o despertador que vibra, a campainha que aciona luz, o uso de fax em vez de telefone, o tipo de piada que se conta etc. (2007, p. 45).

A "cultura surda" é difundida e propagada como sendo exclusivamente dos visossinalizante, enquanto toda e qualquer participação de outros grupos são, terminantemente, excluídas do conceito. Assim sendo, a geração de cultura na surdez estaria restrita aos visossinalizantes e aos profissionais da área, não admitidos outros tipos de participações que não 
sejam regidas pela surdez, como se a criação do conceito estivesse ligado apenas a grupos específicos.

Segundo Santana (2007, p. 47) com base em Kozlowki, o surdo seria um ser bilíngue, o que lhe geraria uma dupla cultura, inserindo assim esse sujeito ao chamado ser bi-cultural. Esse biculturalismo seria, então, gerado em função da educação bilíngue que o visossinalizante recebe, ou deveria receber. Refere-se ao conjunto de significações simbólicas construídas em torno da língua de sinais, seus usos e "estratégias de códigos sociais utilizados de maneira comum pelo visossinalizante para viverem numa sociedade feita por e para ouvintes".

$\mathrm{Na}$ realidade, tal proposição está fundada na adaptação dos modos de existências dos ouvintes para serem vividas pelos visossinalizantes, tornando, assim, uma cultura de adaptações às diferenças e de produção de elos sociais. A realidade e a legitimação da noção de cultura surda, segundo Santana (2007, p. 47), têm sido alvo de muitas críticas, “algumas com razão", em virtude dos aspectos dessa cultura se firmarem mais como um sistema que se deriva dos modos de existência dos ouvintes do que uma cultura realmente original e autônoma.

Karin Strobel (2013) traz a cultura como algo que permite ao homem se adaptar ao meio em que vive e também adaptar esse meio ao próprio homem. É baseado nessa premissa que a pesquisadora desenvolve a tese de que a surdez não é um fator biológico, e sim um fator cultural. Desta forma, a surdez não é percebida como deficiência, mas como diferença cultural.

A cultura surda, para Strobel (2013), é, então, um modo do sujeito visossinalizante entender o mundo e modificá-lo a fim de torná-lo acessível e habitável, ajustando-o, assim, com as suas percepções visuais, que irão contribuir para a definição das identidades surdas e das almas das comunidades surdas. Para a autora, isso significa que abrange a língua, as ideias, as crenças, os costumes e os hábitos do povo surdo, nos trazendo a ideia de Cultura em Tylor (CASTRO, 2005).

A autora cita uma série de itens denominados por ela como "artefatos culturais", sendo eles: a experiência visual do sujeito; o desenvolvimento linguístico; a família; a literatura surda; a vida social e esportiva; as artes visuais; a política e os materiais. A autora ainda faz alguns apontamentos a respeito da representação imaginária sobre a cultura surda. Para a pesquisadora, os ouvintes têm dificuldade de aceitar o termo e ainda pensam que somente o que fazem é cultural. 


\subsection{Identidades surdas: definições}

Além da literatura histórica, da língua, dentre outros elementos já apresentados, a identidade é condicionante e essencial para o visossinalizante, uma vez que, para ele, é a partir da definição de identidade que o sujeito adquire a cultura surda. No texto As diferentes identidades surdas, de autoria da professora surda Gladis Perlin (Texto de circulação restrita), há uma exposição categorizada em forma de itens, para a identificação das diferenças entre as identidades que os surdos podem ter ou "portar".

Segundo Perlin (Texto de circulação restrita), a identidade surda é, essencialmente, política surda. Está presente nos sujeitos que pertencem à comunidade surda e apresentam uma série de características culturais, tais como experiência visual, que determina comportamento, cultura e língua; carregam a língua de sinais e se comunicam exclusivamente de forma visual; aceitam-se como visossinalizantes; passam aos outros sua cultura; assumem posição de resistência; assumem posicionamento de busca por uma identidade cultural; a escrita obedece à estrutura da língua de sinais, ou seja, seu português é "deformado" em virtude da gramática peculiar da língua de sinais; assimilam pouco ou não conseguem assimilar a ordem da língua falada, por dificuldade de entendêla; têm suas comunidades, associações, entre outras entidades que compartilham entre si suas dificuldades, aspirações, utopias; usam tecnologias diferenciadas e tem uma forma peculiar de se relacionar com outras pessoas ou animais.

A identidade surda híbrida é determinada por doenças, acidente ou outro tipo qualquer de mazela que leva uma pessoa nascida ouvinte a se tornar surdo. São características desse tipo de identidade surda: o conhecimento da estrutura da língua oralizada com possibilidade de captação da mensagem na mesma; o uso da língua oral maior que a de sinais; a assimilação do comportamento de visossinalizante; o convívio pacífico com as identidades surdas. Podem ainda existir, segundo Perlin (Texto de circulação restrita), sujeitos com essa identidade que não assimilam a ordem da língua falada; que apresentam escrita condicionada à estrutura sintática da língua de sinais; que 
participam das entidades organizadas do meio; que aceitam-se como surdos e, ainda, que apresentam formas diferentes de relacionamento.

Para Perlin (Texto de circulação restrita), os surdos que não têm contato nenhum com a comunidade surda são considerados de identidade surda flutuante e têm as seguintes características: seguem a representação da identidade ouvinte; dependem dos ouvintes e de seus princípios; não participam da comunidade surda, associações e lutas políticas; desconhecem ou rejeitam a língua de sinais; orgulham-se de falar corretamente; resistem à língua de sinais e à cultura surda; não se identificam como visossinalizantes; são vitimados pela ideologia oralista e, mesmo sendo visossinalizantes, não utilizam as tecnologias dos visossinalizantes.

Uma identidade surda embaçada é a representação da surdez estereotipada ou onde há total desconhecimento da surdez como uma questão cultural. Segundo Perlin (Texto de circulação restrita), é caracterizada por surdos que não compreendem a fala e não conseguem captar a representação de identidade ouvinte; não têm condições de uso da língua de sinais; são considerados incapazes; sua condição de vida está condicionada ao ouvinte; o visossinalizante é considerado deficiente, incapaz, inerte e revolto; há casos de aprisionamentos pela família; há falta de informação, predominando a opinião do médico, e os visossinalizantes ainda podem ser tidos como deficientes ou retardados mentais.

Há os visossinalizantes que viveram em ambientes sem contato com a identidade surda ou se afastaram dela. Esta identidade surda é considerada de transição. São marcas desse sujeito: transitar entre identidades; não adquirir a cultura surda na infância; mudar a situação identitária quando entram em contato com identidades ou cultura surdas, passando a rejeitar a identidade ouvinte. Embora, segundo Perlin (Texto de circulação restrita), esse sujeito passa por uma "desouvintização", a transição de identidade é sempre perceptível; a comunicação visual/oral cede lugar à visual/sinalizada. A identidade surda de diáspora é divergente em relação à identidade surda de transição. Ela está presente em visossinalizantes que transitam de um país a outro, de um estado a outro, ou, ainda, de um grupo visossinalizante para outro.

A última identidade surda é a intermediária. Para Perlin (Texto de circulação restrita), as pessoas marcadas por esta identidade surda não têm sua captação de mensagens estritamente na 
experiência visual, fator que determina a identidade surda, bem como a cultura surda. São características: apresentar porcentagem de surdez, mas viver como ouvintes; utilizar aparelhos de audição; importar-se com treinamentos auditivos; buscar amplificadores de som; não usar intérpretes; posicionar-se contra o uso de intérpretes, não entendendo a necessidade da língua de sinais e ter dificuldade de encontrar sua identidade, uma vez que nem é visossinalizante tampouco ouvinte.

\section{SINGULARIZAÇÃO DO SER SURDO: HIPÓTESES}

Guattari e Rolnik (1996) afirma que tudo o que é produzido pela subjetivação capitalística, desde o que nos chega pela linguagem, pela família e pelos equipamentos que nos rodeiam, são sistemas de conexão direta entre as grandes máquinas produtivas, as máquinas de controle social e as instâncias psíquicas que definem a maneira de perceber o mundo. Para contrapor os processos de subjetivação capitalística, Guattari e Rolnik (1996) propõem modos de subjetivação singulares. Para os autores, a subjetivação singular é

[...] uma maneira de recusar todos esses modos de encodificação preestabelecidos, todos esses modos de manipulação e de telecomando, recusá-los para construir, de certa forma, modos de sensibilidade, modos de relação com o outro, modos de produção, modos de criatividade que produzam uma subjetividade singular (GUATTARI; ROLNIK, 1996, p. 17).

A micropolítica e a cartografia são ou funcionam como platôs, zonas de intensidade contínua, ou seja, linhas ligadas a determinadas dimensões de multiplicidades. Seriam linhas de fuga, círculos de convergência, cadeias moleculares, estratos, etc., que não pretendem um devir de uma ciência, mas apenas agenciamentos maquínicos de desejo e coletivos de enunciação, segundo Rafael Estrada Mejía. A micropolítica, para o autor, repousa em uma concepção singular do corpo e do desejo, nas relações entre as forças ativas e reativas do mesmo (MEJÍA, 2012, p. 03).

Para os autores, a micropolítica é a reprodução de aspectos dos macros agenciamentos no micro, ou seja, na subjetividade singular. A imersão do cidadão em um ambiente enunciativo faz com que o mesmo passe a reproduzir na infraestrutura aquilo que está na superestrutura. A 
micropolítica apresenta também a capacidade de resistência, de contaminar, de mudar a subjetividade das pessoas.

\subsection{Hipótese 1: cotidiana e acadêmica}

Trazendo à baila o agenciamento "identidades surdas" e suas concepções que provoca no ser visossinalizante uma aversão a tudo que se refere ao resto do mundo, que faz com que o sujeito recuse a escrita, inclusive a Escrita de Língua de Sinais - ELS, a oralização e a leitura labial, que, segundo Vilma Geni Slomski (2012), são elementos que fazem parte do tão sonhado bilinguismo, que na realidade está longe de ser alcançado, em função do distanciamento do ser visossinalizante do que realmente seja ele, em função da subjetividade capitalística plantada em seu existir.

Assim sendo, a aquisição da escrita e dos demais aspectos do bilinguismo apontados por Slomski (2012) seria uma forma de singularização do ser visossinalizante. A apropriação do bilinguismo o favoreceria em seu desenvolvimento acadêmico, no acesso à educação superior e, ainda, à permanência e ascensão às mais altas esferas da educação. Atualmente tem ficado restrito. Um dos principais empecilhos que barram o acesso do visossinalizante ao trabalho (cotidiano) e a escola (acadêmico) é justamente a escrita.

Sem conseguir se comunicar oralmente no mercado de trabalho, o visossinalizante tem sido alocado em funções que não demandam comunicação linguística. Não é difícil encontrar surdos em grandes empresas, em subempregos, muitos deles em condições subumanas. No âmbito acadêmico não é muito diferente. Os visossinalizantes que conseguem adentrar os limites do ensino superior não conseguem ter profundidade conceitual/teórica em sua formação, determinadas por diversos fatores, sendo o principal deles, a falta de compreensão da escrita e, em muitos casos, a ausência dela. 


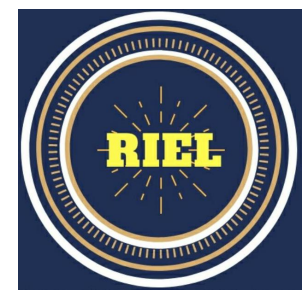

Figura 01 - Poema produzido em Libras e grafado pela VisoGrafia. "O abraço do sol - O pôr do sol é o momento em que o sol me abraça e carinhosamente me diz adeus"
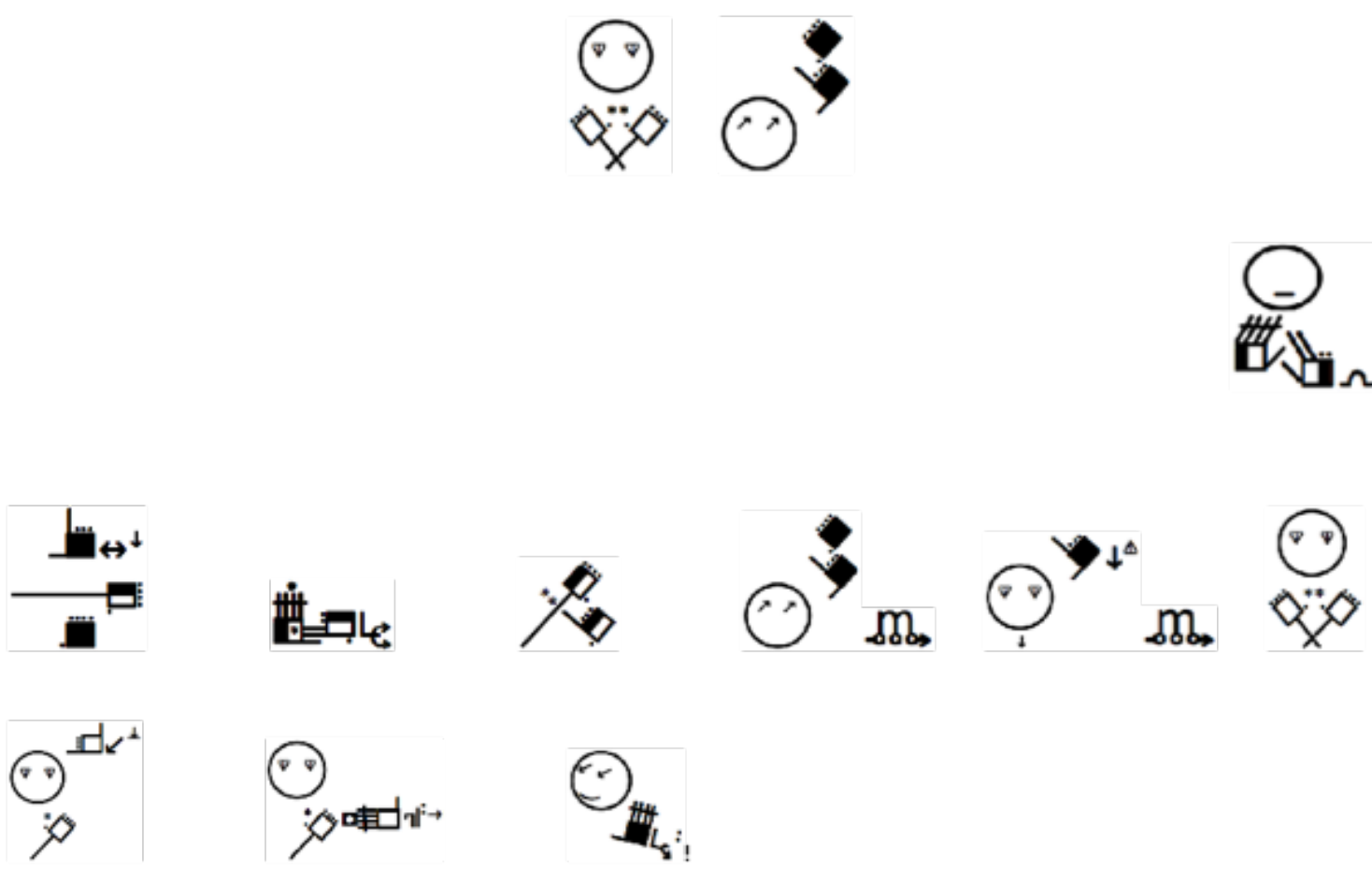

Fonte: Cao Benassi (2019)

A aquisição da escrita, tanto da Língua Portuguesa quanto, e, principalmente, da escrita de língua de sinais por parte do visossinalizante seria então uma micropolítica que o singularizaria, causando uma profunda transformação em seu desenvolvimento acadêmico. Baseado em diversos estudos a esse respeito, poder-se-ia afirmar que o mesmo constituiria uma fuga de uma rigidez identitária que implica num ser fabricado que é incapaz de compreender completamente a escrita ou dela se apropriar. 


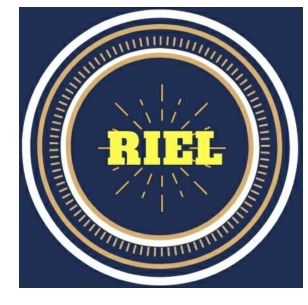

\subsection{Hipótese 2: artística e cultural}

Apesar das artes dos surdos ainda serem incipientes, elas existem. Segundo Strobel (2012), as expressões mais significativas na surdez são as artes visuais - compreendendo as artes plásticas e o teatro - compõe os meios de expressão artística que sintetizam as emoções, as histórias e a cultura dos visossinalizantes. No entanto, percebe-se que a mesma se restringe a demonstrar a vaidade e o apreço pelos agenciamentos em torno da surdez.

Figura 02 - À esquerda: tela criada pelo artista surdo nepalês Pratigya Shakya, que sintetiza a repulsa pelo implante coclear, agenciamento comum aos surdos padronizados. À direita: foto de uma apresentação teatral de surdos, que enfatiza a dominação "ouvintista" e opressão do surdo, sob a coordenação do ator Nelson Pimenta.
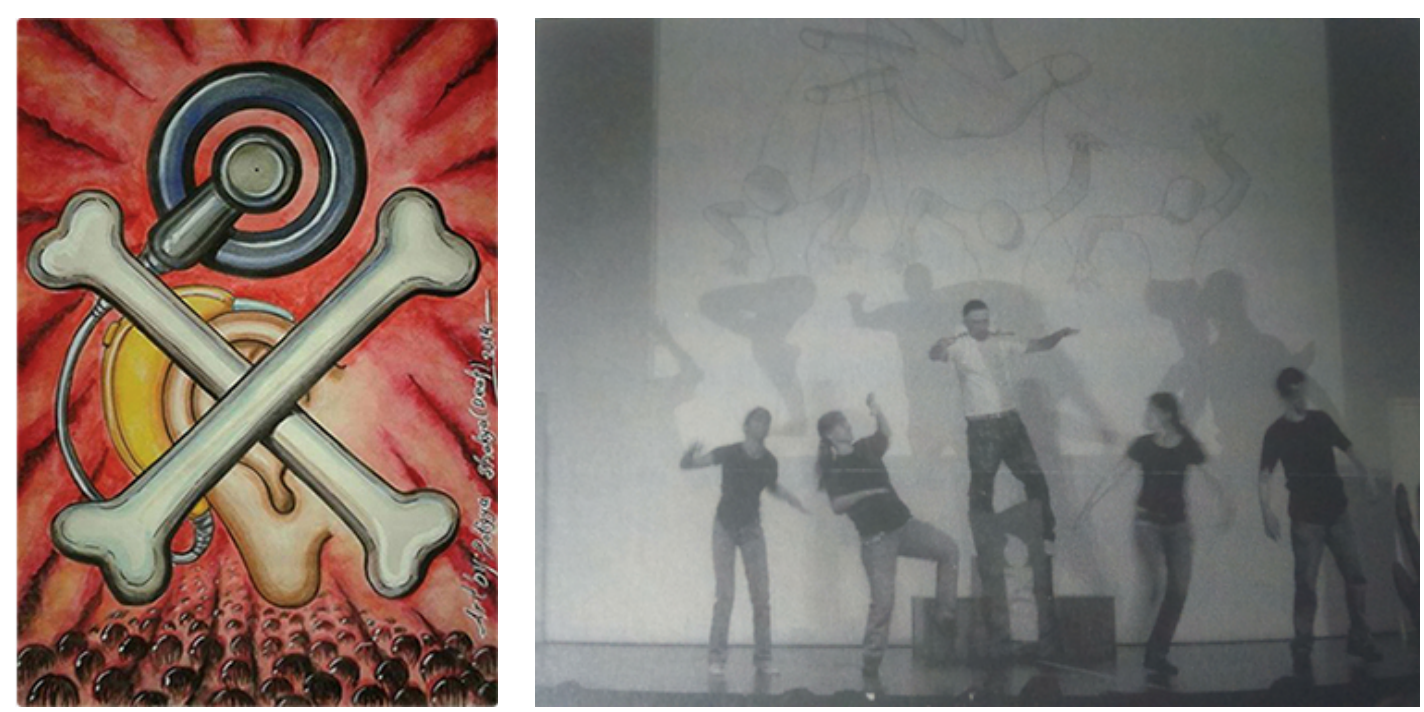

Fonte: Strobel (2012, p. 84).

No âmbito literário, o que é chamado de "literatura surda" é um dos temas tão controversos quanto as identidades e cultura surda. Isso porque a literatura surda trata, em sua grande maioria, de produções adaptadas dos grandes clássicos universais, nos quais, seus personagens principais têm sua essência adulterada, ou seja, o principal personagem da obra é transformado em surdo, como por exemplo, a Cinderela surda, Chapeuzinho Vermelho surda, entre outros, para que os surdos 


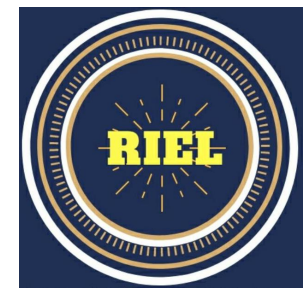

possam se identificar com a trama. Em uma análise preliminar, em relação às artes na surdez, principalmente no que diz respeito à arte literária, não há uma criação autêntica e original, e, quando esta existe, ela está a serviço dos agenciamentos capitalísticos.

A música é uma das artes menos aceitas pelos visossinalizante e, segundo os estudiosos visossinalizantes, só é possível ao sujeito com surdez por uma via intercultural. No entanto, nos últimos anos muitos visossinalizantes despertaram para essa prática, provando que a música é passível de assimilação por eles, pois um dos principais parâmetros que a constitui é a vibração, sendo esta perfeitamente captável pelo visossinalizante. São exemplos Evelyn Glennie, a maior expoente visossinalizante no mundo musical; a Banda AbSurdos e a musicista Patrícia Taques.

A arte - e, principalmente, a música - é sem dúvida um dos platôs de fuga da subjetividade serializada, instrumentos pelos quais os visossinalizante poderão, por meio de sua aquisição, tornam-se singulares. Isso não significa que deixarão de ser visossinalizantes, ou que estarão sendo normalizados por processos de ouvintização. Ao contrário, se tornarão únicos por outros modos de existência, por eles ainda pouco explorados.

Figura 03 - Tecladista visual Patrícia Taques.

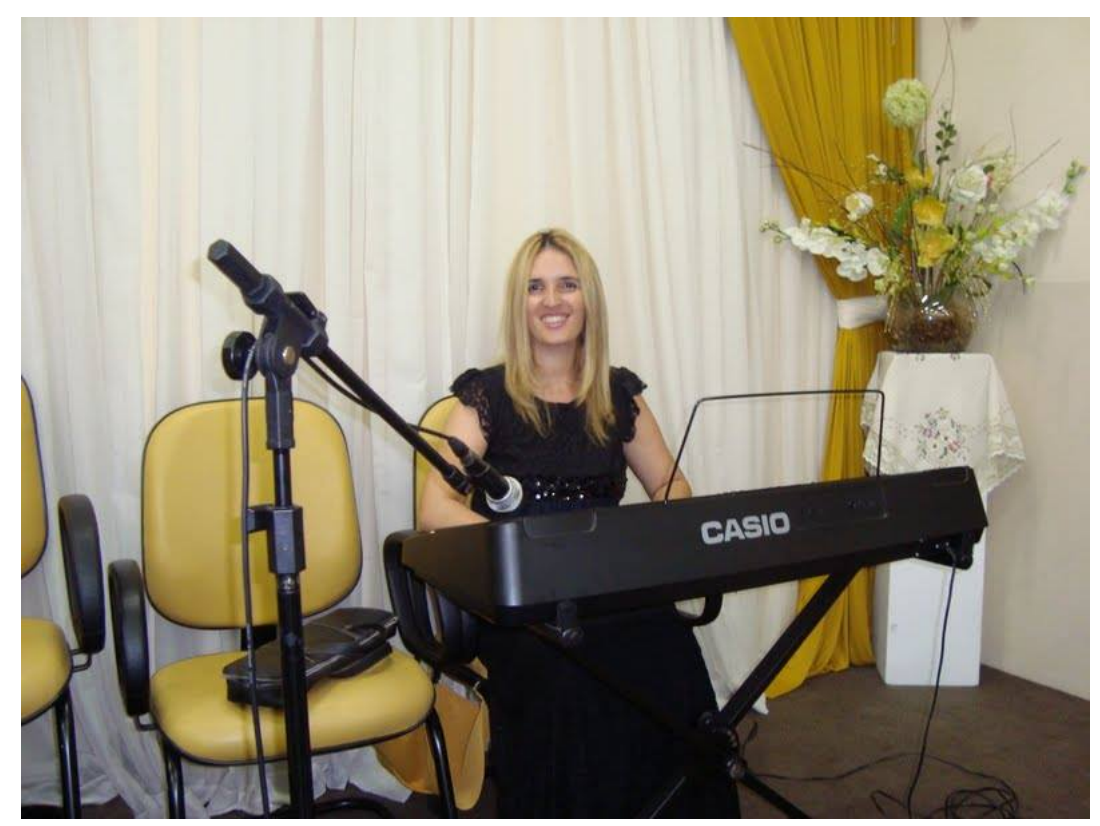

Fonte: Acervo particular do autor (2019) 


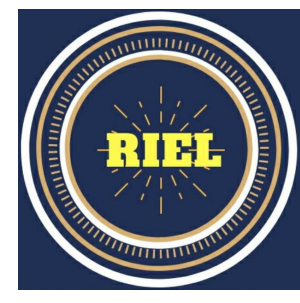

\section{5. ÚLTIMAS PALAVRAS}

Observações e reflexões preliminares apontam que os agenciamentos de identidades e cultura surda, tem padronizado a subjetividade do visossinalizante, fazendo com que o mesmo se recuse aos principais recursos linguísticos dos quais depende para transitar confortavelmente entre os sujeitos oralizados. É comum recusas ainda mais absurdas, como por exemplo, se negar a pagar taxas de inscrição em eventos, por considerar que esse aspecto não faz parte da cultura surda, bem como alegar que alguém perdeu a identidade e a cultura surdas porque assumiu algum aspecto do mundo "ouvinte".

A principal barreira que impede a efetivação das expressões artísticas dos visossinalizante, certamente, é a falta de um instrumento simbólico de fixação. Sem uma escrita fluente, o visossinalizante não tem como fixar sua produção artística, principalmente, a literária, sendo mais fácil adaptar que criar. Sendo assim, percebo que se faz necessária a aquisição da ELS e, posteriormente, a escrita da Segunda Língua - L2, para que de fato o ser visossinalizante possa se singularizar.

Este foi apenas um esboço da pesquisa proposta ao Programa de Pós-graduação em Estudos de Cultura Contemporânea - ECCO, da UFMT. De antemão, percebo que, além de complexa, a temática é também muito polêmica. Conhecendo o meio, tenho certeza que terei grandes embates durante e depois da realização da mesma, pois tanto os visossinalizantes, quanto grande parte dos profissionais envolvidos com eles, usam as identidades e cultura surdas como um agenciamento de proteção [...] por medo da marginalização na qual corremos o risco de ser confinados quando ousamos criar qualquer território singular [...] acabamos reivindicando um território no edifício das identidades reconhecidas (GUATTARI; ROLNIK, 1996, 12).

\section{REFERÊNCIAS}

BRASIL. Lei $\mathrm{n}^{\mathrm{o}}$ 10.436, de 24 de outubro de 2001. Dispõe sobre a Língua Brasileira de Sinais Libras e dá outras providências. Diário Oficial da União, 18 jan. 2002. Seção 1, p. 31. 
CASTRO, C. Evolucionismo cultural: textos de Morgan, Tylor e Frazer. Rio de Janeiro: Jorge Zahar Ed., 2005.

DUARTE, A. S. Empréstimos linguísticos da Língua Brasileira de Sinais - LSB. Revista Diálogos: linguagens em movimento, ano I, n. I, 2013.

GUATTARI, F. ROLNIK, S. Micropolíticas: cartografias do desejo. 4ª ed. Petrópolis: Vozes, 1996.

MEJÍA, R. E. Micropolíticas, cartografias e heterotopias urbanas: derivas teórico-metodológicas sobre a aventura das (nas) cidades contemporâneas. Revista Espaço Acadêmico, n. 132, ano XI, 2012.

PERLIN, G. As diferentes identidades surdas. Texto de circulação restrita, s/d.

SAHLINS, M. Ilhas de histórias. Rio de Janeiro: Jorge Zahar Editor, 1997.

SANTANA, A. P. Surdez e linguagem: aspectos e implicações neurolinguísticas. São Paulo: Plexus, 2007.

SLOMSKI, V. G. Educação bilíngue para surdos: concepções e implicações práticas. Curitiba: Juruá, 2010.

STROBEL, K. As imagens do outro sobre a cultura surda. 3ª ed. Florianópolis: Ed. UFSC, 2013.

ANEXO - Autorização do uso da imagem

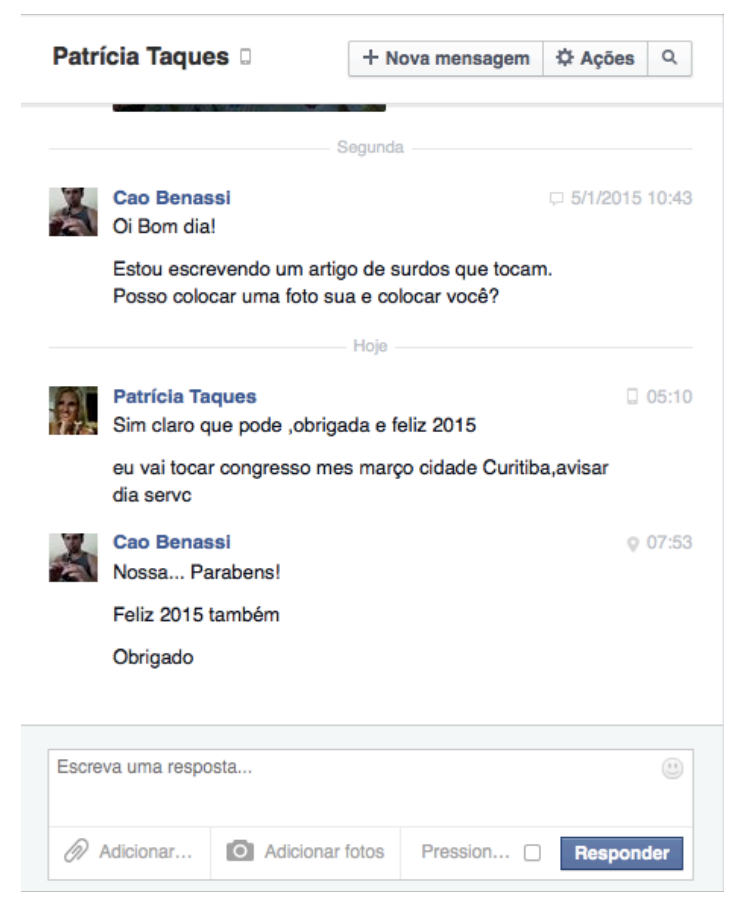

